\title{
Accuracy and Efficiency of Conventional Ground Sprayers in Iran
}

\author{
A. SHEIKHI-GARJAN ${ }^{1}$, A. HOSSEINI-GHARALARI ${ }^{*}$, M. MAHJOB ${ }^{2}$, M. RASHID ${ }^{3}$, \\ Q. SABAHI ${ }^{4}$, M. SAFARI ${ }^{5}$, F. JALILYAN ${ }^{2}$ and R. ARBABTAFTI ${ }^{1}$ \\ ${ }^{1}$ Agricultural Entomology Research Department, Iranian Research Institute of Plant Protection, \\ Agricultural Research, Education and Extension Organization (AREEO), Yaman St., Chamran Hwy., \\ P.O. Box 19395-1454., Tehran, Iran \\ ${ }^{2}$ Agricultural and Natural Resource Research Center of Kermanshah Province, Agricultural Research, \\ Education and Extension Organization (AREEO), Kermanshah, Iran \\ ${ }^{3}$ Tehran Payam-e-Noor University \\ ${ }^{4}$ Plant Protection Department, College of Agriculture and Natural Resources, \\ University of Tehran, Karaj, Alborz, Iran \\ ${ }^{5}$ Iranian Agricultural Engineering Research Institute, Karaj, Iran
}

(Received: 22 August 2016; accepted 07 September 2016)

\begin{abstract}
Sunn pest, Eurygaster integriceps, is a key pest of wheat and barley in Iran. At present, infested areas are treated with ground sprayers. A survey was conducted to evaluate the efficiency and calibration accuracy of ground hydraulic sprayers in Iran. The results showed that the motorized lance sprayer and manually operated sprayer were the most conventional sprayers, and fenitrothion EC 50\% and deltamethrin EC $2.5 \%$ were the conventional insecticides against sunn pest in Kermanshah province. The mean efficacy percentage was $88 \%$ and $35 \%$ against nymphs and overwintered adults, respectively. In motorized lance sprayers, there were $5 \%$ and $90 \%$ overdosage of fenitrothion and deltamethrin, respectively; while, in manually carried sprayers, there were $5 \%$ and $25 \%$ overdosage of fenitrothion and deltamethrin, respectively. Applied dosages were 5-20\% and 25-90\% more than recommended dosages of fenitrothion and deltamethrin, respectively. Errors in effectiveness and applied dosage were higher in motorized lance sprayer than manually carried sprayers.
\end{abstract}

Keywords: Eurygaster integriceps, insecticides, application, wheat, calibration.

Wheat and barley are important crops in the Near East, Middle East, and South-Western Asian countries including Iran. They are attacked by several species of bugs including sunn pest, Eurygaster integriceps Put. (Heteroptera: Scutelleridae). Annually, more than 15 million hectares of cereal fields are damaged by sunn pest in the world. The pest has one generation per year with an obligatory diapause during the adult stage (Alexandrov, 1947; Radjabi, 2000). Sunn pest affects both quality and quantity of the yield. Yield loss may exceed 20-30\% in barley and 50-100\% in wheat. Adult bugs attack leaves and central shoots or spikes of wheat in early spring. Damaged parts become brown or white. When the damage takes place at the early growth stage of wheat, shoots die before spike formation, and the plant reacts by producing new shoots which finally produce spikes with few grains. High population of overwintered adults can considerably reduce yield (Javahery,

* Corresponding author; e-mail: ahosseinig@gmail.com 
1995; Donskoff, 1996; Radjabi, 2000). The progeny of the overwintered adult injects salivary enzymes into grain that cause qualitative loss. The enzyme breaks down gluten and reduces baking quality of flour (Moore, 1998; Hariri et al., 2000).

In Iran, 2.4 million hectares were sprayed against sunn pest in 2011. Less than $30 \%$ of treatment was against overwintered adults and the rest was against nymphs and new generation (Rashidi et al., 2011). During the last decade, fenitrothion EC 50\% and deltamethrin EC 2.5\% were conventional insecticides for the control of sunn pest. The application of fenitrothion in Iran goes back to 4 decades ago; however, it is one decade that deltamethrin is applied against sunn pest (Sheikhigarjan et al., 2009).

During the last two decades in Iran, the chemical control against sunn pest by farmers has been carried out by ground sprayers (Rashidi et al., 2011). Ground spraying seems more effective than aerial spraying, due to lower spraying elevation and lower risk of exo-drift (Mathews, 2005). At present, deltamethrin is the dominant insecticide against sunn pest in Iran. Previously, deltamethrin was used more often in the Southern provinces, whereas in the Western provinces, fenitrothion was mostly applied (Rashidi et al., 2010, 2011).

Chemical control may have deleterious side effects on natural enemies (Voegelé, 1996). In general, application of insecticides on overwintered adults negatively affects natural enemies' population by reducing sunn pest egg parasitism rate from $86.9 \%$ to 8.3\% (Rosca et al., 1996).

The ground sprayers which are used in chemical control of sunn pest are as follows: motorized lance sprayer on trolley or mounted on tractor, manually carried sprayers such as compression knapsack sprayer, lever-operated knapsack sprayer and air assistant sprayers (Sheikhigarjan et al., 2006). The problems associated with these sprayers are as follows: wrong direction of spraying, uneven distribution of insecticide over target areas, overdosage, insecticide drift and miscalibration of sprayers. In Iran, numbers of people who can deal with and rectify the problems of the sprayers are not many (Erman et al., 2007).

The goals of this research were to: 1) quantify spraying accuracy of accessible sprayers against sunn pest in Kermanshah province of Iran, 2) determine the application rate and efficacy of fenitrothion and deltamethrin against sunn pest when sprayed with different sprayers in the field.

\section{Materials and Methods}

Locations: The research was conducted in seven sunn pest-infested locations of Kermanshah (Iran) as follows: 1) Bashgan ( $\left.34^{\circ} 37^{\circ} 00^{\prime} \mathrm{N}, 45^{\circ} 45^{\prime} 00^{\prime} \mathrm{S}\right), 2$ ) Faraman

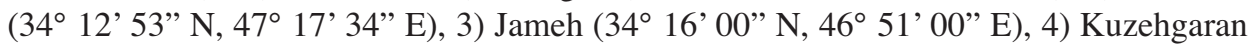

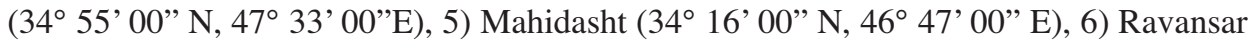

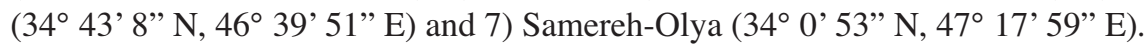

Insecticides: The efficacy of two conventional insecticides, fenitrothion EC 50\% (at 1 1/ha) and deltamethrin EC $2.5 \%$ (at 0.3 1/ha), were evaluated against nymph and adult sunn pest. The insecticide efficacies were evaluated at the stages of overwintered adults and nymphs (new generation). In total, 30 infested fields were chosen for the experiment. In the treated plots, the density of the pest was above the economic threshold (3-5 adults/ 
$\mathrm{m}^{2}$ ) (Rashidi et al., 2011). In the tested fields, farmers applied either or both insecticides in rotation during one season; therefore, the mortality rates were not related to the specific above-mentioned insecticides alone, but indicating the outcomes of a "package" of treatments. The number of overwintered adults and nymphs were recorded one day before application (Table 1) and 20 days after application. The overwintered adults and nymphs were sampled with a $1 \times 1 \mathrm{~m}$-quadrate (with 10 replications per hectare) and insect net (50 netsweeps per hectare), respectively. The efficacy was calculated based on the Henderson-Tilton formula (Henderson and Tilton, 1955):

$$
\text { Efficacy } \%=100 \times[1-(T a \times C b) /(T b \times C a)]
$$

Where, $T a$ is the number of insects in treated plot after treatment, $C b$ is the number of insects in control plot before treatment, $T b$ is the number of insects in treated plot before treatment, and $\mathrm{Ca}$ is the number of insects in control plot after treatment.

\section{Table 1}

Mean ( $\pm \mathrm{SE}$ ) density $/ \mathrm{m}^{2}$ of overwintered adults and nymphs of sunn pest, Eurygaster integriceps, before treatment with insecticides at different locations of Kermanshah province (Iran)

\begin{tabular}{|c|c|c|c|c|}
\hline \multicolumn{2}{|c|}{ Nymphs } & \multicolumn{2}{|c|}{ Overwintered adults } & \multirow[b]{2}{*}{ Location } \\
\hline Date of treatment & Mean $( \pm \mathrm{SE})$ density $/ \mathrm{m}^{2}$ & Date of treatment & Mean $( \pm \mathrm{SE})$ density $/ \mathrm{m}^{2}$ & \\
\hline 31 May & $32.5 \pm 3.22$ & 3 April & $10 \pm 2$ & Faraman \\
\hline 1 Jun & $38 \pm 1.7$ & 8 April & $10 \pm 2.5$ & Bashgan \\
\hline 2 Jun & $33.43 \pm 3.31$ & - & $\mathrm{NA}^{*}$ & Jameh \\
\hline 30 May & $26 \pm 2$ & - & NA & Ravansar \\
\hline 31 May & $20 \pm 3$ & - & NA & Samereh-Olya \\
\hline- & NA & 4 April & $8.5 \pm 1.7$ & Mahidasht(1) \\
\hline- & NA & 5 April & $7 \pm 1.4$ & Mahidasht(2) \\
\hline- & NA & 9 April & $4 \pm 0.9$ & Kuzehgaran \\
\hline
\end{tabular}

* NA $=$ Non-available due to technical problems

Sprayers: The efficiency and calibration accuracy of 25 ground hydraulic sprayers, including 15 motorized lance sprayers and 10 knapsack sprayers, as the conventional sprayers, were studied. The concentrations of fenitrothion and deltamethrin in the tank were calculated based on the conventional field operation of farmers. For each sprayer, the spray volume per hectare was estimated by determining spray flow rate per minute at three different spraying times. Time needed for spraying one hectare was calculated based on movement of the operator over a 100-meter distance. The cone nozzle was used in all tested sprayers. During spraying, the nozzle was approximately $50 \mathrm{~cm}$ above the canopy. The water sensitive papers were used for estimating the swath widths and spraying uniformity. The cards were collected after spraying and number of droplets $/ \mathrm{cm}^{2}$ were counted. A questionnaire was prepared for farmers of the above-mentioned locations and 
the following data were collected: applied insecticide, insecticide dosage per hectare, type of sprayer, volume of the sprayer tank, number of applications against sunn pest. Efficacies were calculated and analyzed by ANOVA (PROC GLM) followed by Duncan test in SAS Ver. 9.2 (SAS Institute Inc. 2002). Difference between motorized lance sprayer and manually carried sprayer regarding the following factors were analyzed by T-test: applied dosage by farmers, overdosage rates, spraying velocity, swath width, and time needed to spray one hectare and efficacy coefficient (i.e. how many hectares per 8 hours).

\section{Results and Discussion}

The conventional application of deltamethrin EC 2.5\% and fenitrothion EC 50\% against overwintered adults of sunn pest did not result acceptable control levels in the studied locations based on the local sprayer types, farmers experience and weather condition. The low efficacy could be related to both poor application technology and biological factors. After chemical application, the overwintered adults of sunn pest may immigrate from hibernation sites to the fields or may move among fields. In an infested field, overwintered adults spend half of lifetime on the plant and the other half on soil surface (Radjabi, 2000), resulting less exposure time of overwintered adults to insecticides and low mortality rate. Moreover, the period of chemical control of overwintered adults is often coincided with high precipitation which increases rain fastness on the foliage (Wilson, 2004). The efficacy of applications against new generation (nymphal stage) of sunn pest was different. The wheat fields which were treated once and twice had $79 \%$ and $97 \%$ efficacy, respectively. The precipitation rate is low during nymphal stage of sunn pest. Sunn pest nymphs ( $2^{\text {nd }}$ and $3^{\text {rd }}$ instars $)$ are more susceptible to the insecticides than overwintered adults (Sheikhigarjan et al., 2002). Furthermore, the nymphs are often active on the plants (Javahery, 1995; Radjabi, 2000). All these factors result higher efficacy of chemical control against sunn pest nymphal stage (ca. 79\%) compared to overwintered stage (ca. $34.96 \%$ ) (Table 2).

Mean efficacy of the insecticides was lower against overwintered adult $(<50 \%)$ compared to nymphs $(<80 \%)$ (Table 2$)$. Chemical control against overwintered adults was the least efficacious in Faraman and Kuzehgaran regions; this could be due to geographical differences (i.e. near or far to hibernation habitats of overwintered adults), precipitation rate, application method and experience of operators for pesticide application and the above-mentioned biological factors.

The motorized lance sprayer and manually carried sprayer, including compression knapsack sprayer and lever-operated knapsack sprayer, were conventional sprayers in Kermanshah province (Iran). The error rate of application (i.e. overdosage rate) of motorized lance sprayer was more (ca. three to four times) than manually carried sprayer (Table 3). Other studies confirmed the above observation and showed that the spray uniformity and quality of MS sprayers were low (Fallahjedi, 2000; Gerami, 2005; Safari, 2009). However, spray volume of motorized lance sprayer was twice the spray volume of manually carried sprayer (Table 3). Occasionally, the low efficacy of chemical control against nymphal stage of sunn pest in some locations, can be the result of incorrect time of 
Table 2

Mean ( \pm SE) efficacy of conventional application (fenitrothion and deltamethrin) against overwintered adults and nymphs of sunn pest, Eurygaster integriceps, at different locations of Kermanshah province (Iran)

\begin{tabular}{cccll}
\hline \multicolumn{2}{c}{ Nymphs } & \multicolumn{2}{c}{ Efficacy (\%) } & \multicolumn{2}{c}{ Overwintered adults } \\
\hline $\begin{array}{c}\text { Applied two or three times } \\
\text { (at 5-day intervals) }\end{array}$ & Applied once & & Applied once & Location \\
\hline $98.2 \pm 0.4$ & $77.25 \pm 7.6$ & $25.6 \pm 4.3 \mathrm{bc} \dagger$ & Faraman \\
$94.5 \pm 3.5$ & $82.25 \pm 6.7$ & $40 \pm 7 \mathrm{ab}$ & Bashgan \\
$97.2 \pm 1.1$ & $78 \pm 6.4$ & $\mathrm{NA}^{*}$ & Jameh \\
$99 \pm 0.5$ & $87.5 \pm 6.2$ & $\mathrm{NA}$ & Ravansar \\
$97.2 \pm 1.8$ & $69.7 \pm 4$ & $\mathrm{NA}$ & Samereh-Olya \\
$\mathrm{NA}$ & $\mathrm{NA}$ & $55 \pm 6.7 \mathrm{a}$ & Mahidasht(1) \\
$\mathrm{NA}$ & $\mathrm{NA}$ & $35 \pm 3.8 \mathrm{~b}$ & Mahidasht $(2)$ \\
$\mathrm{NA}$ & $\mathrm{NA}$ & $16 \pm 7.5 \mathrm{c}$ & Kuzehgaran \\
$0.75_{4,15}(0.542)$ & $1.03_{4,15}(0.426)$ & $6.45_{4,25}(0.001)$ & $F_{\text {df }}(P)$ \\
\hline
\end{tabular}

* NA $=$ Non-available due to technical problems

$\dagger$ Means followed by the same letters in a column were not significantly different based on Duncan's test $(\alpha=0.05)$

application. Early or late application against nymphal stage might coincide with predominant stages of egg or new adult sunn pest.

There was overdosage application of insecticides in all tested sprayers. In both types of sprayers, deltamethrin and fenitrothion was applied $60 \%$ and $18.6 \%$ more than

\section{Table 3}

The dosage and overdosage rates of fenitrothion EC500 and deltamethrin EC25 in the motorized lance sprayer (MS) and compression knapsack sprayer (KS) applied against overwintered adults and nymphs of Sunn Pest, Eurygaster integriceps, in different locations of Kermanshah province (Iran)

\begin{tabular}{|c|c|c|c|c|c|c|c|}
\hline \multirow[b]{2}{*}{$\begin{array}{l}\text { Sprayer } \\
\text { type }\end{array}$} & \multirow[b]{2}{*}{$\begin{array}{l}\text { Spray volume } \\
(1 / \mathrm{ha})\end{array}$} & \multicolumn{3}{|c|}{ fenitrothion } & \multicolumn{3}{|c|}{ deltamethrin } \\
\hline & & $\begin{array}{l}\text { Applied dosage } \\
\text { by farmers } \\
\text { (ml/ha) }\end{array}$ & $\begin{array}{c}\text { recom- } \\
\text { mended dos- } \\
\text { age } \\
(\mathrm{ml} / \mathrm{ha})\end{array}$ & $\begin{array}{l}\text { overdosage } \\
(\%) \dagger\end{array}$ & $\begin{array}{l}\text { Applied dosage } \\
\text { by farmers } \\
(\mathrm{ml} / \mathrm{ha})\end{array}$ & $\begin{array}{c}\text { Recom- } \\
\text { mended } \\
\text { dosage } \\
(\mathrm{ml} / \mathrm{ha})\end{array}$ & overdosage (\%) \\
\hline MS & $298 \pm 54$ & $1200 \pm 86$ & 1000 & $20 \pm 6.5$ & $571 \pm 49$ & 300 & $90.4 \pm 17$ \\
\hline $\mathrm{KS}$ & $140 \pm 15$ & $1050 \pm 39$ & 1000 & $5 \pm 4.1$ & $375 \pm 20$ & 300 & $25 \pm 6.1$ \\
\hline$t_{\mathrm{df}}(P)$ & $10.6_{24}(0.001)$ & $2.71_{14}(0.016)$ & & $2.71_{14}(0.016)$ & $4.06_{14}(0.001)$ & & $4.06_{14}(0.001)$ \\
\hline
\end{tabular}

$\dagger \%$ Overdosage $=($ applied dosage-recommended dosage $) /$ recommended dosage 
the recommended dosages, respectively (Table 4). In other words, farmers used to apply the insecticides at a rate of $1200 \mathrm{ml}$ per hectare without paying attention to the type of the insecticide or recommended field dosage. This fact was due to recommended dosage of insecticides against sunn pest at several decades age (i.e. $1200 \mathrm{ml} / \mathrm{hectare}$ ) and farmers' resistance in accepting the lower recommended doses of the new insecticides.

\section{Table 4}

Some characteristics of motorized lance sprayer (MS) and compression knapsack sprayer (KS) used in chemical control of sunn pest, Eurygaster integriceps, in Kermanshah province (Iran)

\begin{tabular}{lccccc}
\hline Sprayer type & $\begin{array}{c}\text { Spraying velocity } \\
(1 / \mathrm{min})\end{array}$ & $\begin{array}{c}\text { Tank } \\
\text { volume }(\mathrm{l})\end{array}$ & Swath width $(\mathrm{m})$ & $\begin{array}{c}\text { Time needed to spray } \\
\text { one hectare }(\mathrm{min})\end{array}$ & $\begin{array}{c}\text { Efficacy coefficient } \\
\text { (hectare/8 hr.) }\end{array}$ \\
\hline MS & $10 \pm 3$ & 100 & $20 \pm 3$ & $25 \pm 5$ & $19.2 \pm 4.4$ \\
KS & $1 \pm 0.2$ & $15-20$ & $2.5 \pm 0.5$ & $160 \pm 20$ & $3 \pm 0.38$ \\
$t_{\text {df }}(P)$ & $8.81_{14}(0.001)$ & - & $13.7_{14}(0.001)$ & $18.47_{14}(0.001)$ & $10.83_{14}(0.001)$ \\
\hline
\end{tabular}

The tested motorized lance sprayers included power take off and two-stroke engine types. The sprayer tank capacity of the tested motorized lance sprayers was 100 liters; while sprayer tank with 700, 2000 and 3000 liters of volume can also be found in villages. All tested sprayers did not have perfect manometer. Moreover, most of the farmers did not use manometers, even if they were faultless (Fallahjedi, 2000; Safari, 2009).

As Table 4 shows, the spraying velocity was 10 times more in motorized lance sprayers compared to manually carried sprayer. The swath width was $12.5 \%$ more in motorized lance sprayers compared to manually carried sprayer. Spraying one hectare with motorized lance sprayers was 6.4 times faster than spraying it with manually carried sprayer. In other words, efficacy coefficient of motorized lance sprayers was 6.4 times more than manually carried sprayer.

Safari (2009), found that motorized lance sprayers had the highest spray volume (854.2 1/ha) compared to boom, turboliner and micronair spayers in wheat fields. In this study, the spray volume errors were usually large and more sprayers had 10-16\% error of spray volume rate (Table 4). The mean ( \pm SE) dosages of fenitrothion EC 500 and deltamethrin EC 25 applied by farmers were $20 \%$ and $90 \%$ more than recommended rates (Tables 3 and 4). Another study showed that $64 \%$ of orchard sprayers had errors in spray volume. These errors were within 5-10\% of the recommended rate of application (Derksen and Breth, 1994).

In a manually-operated hydraulic sprayer, application rate and delivery of an insecticide depend on the skill of operator. The spray volume is affected by nozzle output, swath width and operator speed (Matthews, 2005). We observed that the tested operators did not have enough knowledge about sprayers and how to calibrate them correctly; therefore, there is a need to educate Iranian farmers regarding insecticide application.

Derksen and Breth (1994) found that the application errors in chemical control of orchard pests ranged from $56 \%$ under application to $99 \%$ over application. Sheikhigarjan et al. 
(2006, 2009) reported that deltamethrin and fenitrothion have been wasted about $90 \%$ and $20 \%$, respectively, more than their recommended dosages against sunn pest; moreover, they showed that $68 \%$ and $90 \%$ of the studied growers applied fenitrothion and deltamethrin at overdosage rates, respectively. They found that the conventional dosage of fenitrothion was $1.31 /$ ha by operators of lance sprayers against sunn pest. In our study, the overdosage rate was observed in $80 \%$ of the cases, and under dosage of insecticides was observed only in one case.

\section{Conclusion}

In recent years, the government of Iran has tried to import the air assistant sprayers and has encouraged farmers to use them instead of using lance and manually sprayers. Safari (2009) reported that $39.7 \%$ of sprayers were lance sprayers used in wheat fields in 4 provinces under studying. At present, in $60 \%$ of the studied locations of Kermanshah province, motorized lance sprayers and manual sprayers are used by farmers; while, air-assisted sprayers are used in the rest of the locations (Rashidi et al., 2010). Many experts reject using air-assisted sprayers (garden sprayer) against field pests (Matthews, 1999; Matthews, 2005). Optimizing air-assisted sprayers for chemical control of sunn pest needs more research. The pyrethroid insecticides such as deltamethrin have lower LD50 than organophosphorus insecticides, like fenitrothion. They can be applied at low rates while achieving acceptable pest control; therefore, they need more precision in application. Unfortunately, less effort has been applied to assess the actual accuracy of wheat spraying operations. The technology of motorized lance sprayers and manual sprayers go back to 1970s. The spray volume of these sprayers is high and the operators over apply the chemicals. High volume sprayer can increase chemical and fuel consumption, labor cost, crop damage. Over application may increase production costs, excess chemical residuals, high risk of resistance to insecticides and environmental contamination. We hope that motorized lance sprayers and manual sprayers (high spray volume) will be replaced with suitable sprayers equipped with Controlled Droplet Application nozzle (low spray volume) and the operators of sprayers are encouraged to learn the methods of equipment calibration, to significantly reduce the error of application in the crop field.

\section{Acknowledgements}

The authors thank researchers of sunn pest research department, F. Parsi and all executive agents of Department of Plant Protection of Agricultural and Natural Resource of Kermanshah province.

\section{Compliance with Ethical Standards:}

Funding: This study was not funded by any organization.

Conflict of Interest: All authors declare that they no conflict of interest.

Ethical approval: This article does not contain any studies with human participants or animals performed by any of the authors. 


\section{Literature}

Alexandrov, N. (1947): Eurygaster integriceps Put. a Varamine et ses parasites. Entomol. Physiopath. Appl. 5, $29-41$.

Derksen, R. C. and Breth, D. I. (1994): Orchard air-carrier sprayer application accuracy and spray coverage evaluation. Appl. Eng. Agric. 10, 463-470.

Donskoff, M. (1996): Prospects for international cooperation of Sunn Pest research and control. FAO Plant Production and Protection Paper, Rome, Italy, No.138, pp. 17-21.

Erman, A., Sabahoglu, Y., Babaroglu, N. and Canhilal, R. (2007): Aerial vs. ground applications for Sunn Pest management. In: B. L. Parker, M. Skinner, M. Bouhssini and S. Kumari (eds): Sunn Pest Management: A Decade of Progress 1994-2004. Arab Society for Plant Protection, Beirut, Lebanon, pp. 209-213.

Fallahjedi, R. (2000): Structure and application of conventional sprayers of Iran. Agricultural Research, Education and Extension Organization, Nashr-e Amozesh keshvarzi, Karaj, Iran, 150 p.

Gerami, K. (2005): Study on three kinds of sprayers in control of wheat weeds in Ardabil region. MS thesis, Research-Science Department of Islamic Azad University, Tehran, Iran.

Hariri, G., Williams, P. C. and EI-Haramein, F. J. (2000): Influence of pentatomid insects on the physical dough properties and two-layered flat bread baking quality of Syrian wheat. J. Cereal Sci. 31, 111-118.

Henderson, C. F. and Tilton, E. W. (1955): Tests with acaricides against the brown wheat mite. J. Econ. Entomol. $48,157-161$.

Javahery, M. (1995): A technical review of Sunn Pest. First ed. FAO. Rome, Italy, 80 p.

Matthews, G. A. (1999): Application of pesticides to crops. I C Press. UK, 325 p.

Matthews, G. A. (2005): Pesticide application methods. 3rd ed. Blackwell Science, Oxford, UK, 432 p.

Moore, D. (1998): Control of Sunn Pests, particularly Eurygaster integriceps Put. (Hemiptera, Scutelleridae): the role of mycoinsecticides in management schemes. Proc. The First Workshop of Integrated Sunn Pest Control, Ankara, Turkey, 6-9 January 1998.

Radjabi, Gh. (2000): Ecology of Cereal's Sunn Pests in Iran. Agricultural Research Education and Extension Organisation Press, Tehran, Iran, $330 \mathrm{p}$.

Rashidi, A., Nazari, N., Javadipoya, H. and Moein, S. (2010): Final report of Sunn Pest control 2010-2011. Crop Protection Organization of Iran.

Rashidi, A., Nazari, N., Javadipoya, H. and Moein, S. (2011): Final report of Sunn Pest control 2011-2012. Crop Protection Organization of Iran.

Rosca, C., Popov, C., Barbulescu, A., Vonica, I. and Fabritius, K. (1996): The role of natural parasitoids in limiting the level of Sunn Pest populations. FAO Plant Production and Protection Paper, Rome, Italy, No.138, pp. 23-33.

Safari, M. (2009): Technical evaluation of conventional and new sprayers in wheat farms in order to determination of methods and proper machine to use in different regions of country. Final Report of Research Project, Agricultural Research, Education and Extension Organization, Iran.

SAS Institute Inc. (2002): SAS/STAT user's guide. Version 9.1. SAS Institute Inc., Cary, North Carolina.

Sheikhigarjan, A., Keyhanyan, A., Mahjoub, M. and Abdollahi, Gh. (2006): Study on efficacy and calibration accuracy of conventional ground sprayer in Sunn Pest control. Proc. 17th Iranian Plant Protection congress, University of Tehran, Karaj, Iran, 2-5 September 2006, Vol. 1. Pests, 318 p.

Sheikhigarjan, A., Keyhanyan, A. and Moein, S. (2009): Efficiency of sprayer equipped by micronair nozzle (CDA) in chemical control of Sunn Pest nymphs. Appl. Entomol. Phytopathol., Pestic. Spec. Issue, pp. 19-33.

Sheikhigarjan, A., Talebi, Kh., Pourmirza, A., Khalaghani, J. and Radjabi, Gh. (2002): Bioassay of different life stages of Sunn Pest to six insecticides and analysis of data by three methods. Islamic Azad University, Tehran, Iran. J. Agric. Sci. 8, 17-33.

Voegelé, J. (1996): Review biological control of Sunn Pest. FAO Plant Production and Protection Paper, Rome, Italy, No.138, pp. 23-33.

Wilson, M. F. (2004): Optimizing pesticide use. John Wiley and Sons Ltd, United States. 222 p. 